\title{
Ultimate Biodegradation of Industrial Detergent Used in the Upstream Sector of the Nigeria Petroleum Industry in Freshwater, Brackish and Marine Water
}

\author{
Renner Renner Nrior ${ }^{1, ~}$, Lucky Odokuma ${ }^{2}$, Elizabeth Tete ${ }^{1}$ \\ ${ }^{1}$ Department of Microbiology, Faculty of Science, Rivers State University of Science and Technology, Port Harcourt, Nigeria \\ ${ }^{2}$ Department of Microbiology, Faculty of Science, University of Port Harcourt, Port Harcourt, Nigeria
}

Email address:

renner4nrior@gmail.com (R. R. Nrior)

${ }^{*}$ Corresponding author

\section{To cite this article:}

Renner Renner Nrior, Lucky Odokuma, Elizabeth Tete. Ultimate Biodegradation of Industrial Detergent Used in the Upstream Sector of the Nigeria Petroleum Industry in Freshwater, Brackish and Marine Water. International Journal of Ecotoxicology and Ecobiology.

Vol. 2, No. 4, 2017, pp. 134-144. doi: 10.11648/j.ijee.20170204.11

Received: May 19, 2017; Accepted: June 22, 2017; Published: September 22, 2017

\begin{abstract}
Ultimate biodegradability of Industrial detergent; Teepol and Gamazyme used in the upstream sector of the Nigeria petroleum industry were investigated in fresh, brackish and marine water systems. The methodology of ultimate biodegradability estimated from the ratio of Biochemical Oxygen Demand to Chemical Oxygen Demand was used to determine biodegradability. Evaluation of percentage (\%) ultimate biodegradation at day 20; showed T-pol (71.2\%) to be more biodegradable in brackish water system while Gamazyme $(31.1 \%)$ in fresh water system is least. Comparatively, biodegradability potential of the Industrial detergents in the tri-aquatic systems were; Fresh water system: T-pol (46.6\%) > Gamazyme (31.1\%). Brackish water system: Gamazyme BTC (73.1\%) > T-pol (71.2\%). Marine water system: T-pol $(55.6 \%)>$ Gamazyme $(44.7 \%)$. Industrial detergent utilizing bacteria genera isolated and their frequency were; Pseudomonas 35.7\%, Bacillus 30.7\%, Micrococcus $15.4 \%$ and Enterobacter 15.4\% while fungi genera were; Aspergillus, Penicillium, Rhizopusand Mucor. Conclusively, the study showed that Industrial detergent Gamazyme BTC had a very low biodegradation potential in fresh and marine water environment especially in fresh water. Based on these findings; the use of Industrial detergent Gamazyme should be with high caution or discontinued in the upstream sector of the Nigeria Petroleum Industry.
\end{abstract}

Keywords: Ultimate Biodegradation, Industrial Detergent, Teepol, Gamazyme, Marine Water, Brackish Water, Freshwater, Pseudomonas sp, Bacillus sp

\section{Introduction}

Biodegradation is the breakdown of a complex chemical through biological processes. Biodegradation is a term that can be used to described three major types of changes in a molecule, (a) a minor change in the functional groups attached to an organic compound, such as the substitution of a hydroxyl group for a chlorine group: (b) an actual breaking of the organic compound into organic fragments in such a way that the original molecule could be reconstructed; (c) the complete degradation of an organic compound to minerals (Prescott, 2011). Detergents are any soap or non-soap powder, which can be used in both industrial and domestic premises as cleaning agent (Holding, 2005). An increased rate of technological development has brought about the production of these synthetic materials, a factor that has supported the need for an enhanced biodegradability studies. Indeed, the need for these studies has become important especially as a result of consumer use and disposal pattern of these detergent chemicals, prior to discharges into streams, rivers and estuaries. Actually considerable level of detergents biodegradation activity take place in the environment (Lawson and Payne, 1980), such problems have been reported to include: destruction of the external mucus layer that protects fish from bacteria and other pathogens, severe damage to the gills, lowering of the surface tension of the water, algal blooms that releases toxins and decrease oxygen in waterways and decrease in the breeding ability of aquatic organisms. The main contributors to the toxicity of these 
detergents are the sodium silicate solution and the surfactant used as part of the compositions (Holding, 2005). Biodegradability test for assessing the environmental acceptability of synthetic compounds usually employ mixed culture of various organisms (Okpokwasili and Nwabuzor, 1988; Nrior and Odokuma, 2015). The increasing release of organic pollutants by industries causes many health-related problems. However, increased awareness of the harmful effects of environmental pollution has led to a dramatic increase in research on various strategies that may be employed to clean up the environment (Olusola and Benjamin, 2009).

Aquatic ecosystems are also used for human recreation, and are very important to the tourism industry, especially in coastal regions (Fuhrman, 1991). The health of an aquatic ecosystem is degraded when the ecosystem's ability to absorb a stress has been exceeded. A stress on an aquatic ecosystem can be a result of physical, chemical or biological alterations of the environment. Physical alterations include changes in water temperature, water flow and light availability. Chemical alterations include changes in the loading rates of biostimulatory nutrients, oxygen consuming materials, and toxins. Biological alteration include over harvesting of commercial species and the introduction of exotic species. Human populations can impose excessive stresses on aquatic ecosystems. Bacteria from the genera Bacillus, Pseudomonas, Corynebacteriumetc are also present in the marine environment (Ogbulieet al., 2008; Nrior and Odokuma, 2015). The greatest impact seems to be on the aquatic environment in that our natural surface waters; ponds, streams, rivers, estuaries, lagoons, lakes, seas, and oceans with inherent aquatic lives are rather "waste sinks" directly or indirectly for most Nigerian's chemical, food and agricultural and petroleum based industries (NEST, 1991; Nrior and Wosa, 2016 ).

This research is designed to evaluate the biodegradability potential of two brands of industrial detergents (Gamazyme and Teepol) used in upstream sector of the Nigeria Petroleum Industry in freshwater, brackish and marine ecosystem.

\section{Materials and Methods}

\section{Source of Samples}

Water sample

Fresh water samples were collected with ten (10) litre sterile plastic containers from a freshwater ecosystem, Asarama stream in Asarama town, Andoni Local Government Area in Rivers state, Nigeria. The containers were rinsed three times with the water samples to be collected at the site before collection was made. The river serves as the major sources of drinking water.

Brackish water samples were collected with ten (10) litre sterile plastic containers from Azuabie River near Port Harcourt Zoo in Port Harcourt Local Government Area in Rivers State, Nigeria. The containers were rinsed three times with the water samples to be collected at the site before collection was made. The river spans from Rumuogba via Woji, Azuabie town down to Marine Base, Port Harcourt. The river does not only receive faecal (as the coastal dwellers traditionally defecate into the water body), other industrial chemicals, solids and waste water of domestic origin, but also serves as the sink for used drilling fluid, degreasers, dispersants and Industrial detergent waste water.

Marine water samples were collected with ten (10) litre sterile plastic containers from Bonny Sea in Bonny Local Government Area in Rivers State, Nigeria. The containers were rinsed three times with the water samples to be collected at the site before collection was made. The sea spans from Okrika Main River to Bonny Island and empties into the Atlantic Ocean. The sea does not only receive fecal (as the coastal dwellers traditionally defecate into the water body), other industrial chemicals, solids and waste water of domestic origin, but also serves as the sink for used petroleum products and all kinds of effluents.

Source of microorganism for biodegradability test

The microorganisms for the biodegradation study were naturally occurring micro flora in the specified aquatic environment.

\section{Test sample (Industrial detergents)}

The two brands of industrial detergents (Gamazyme and Teepol) were purchased from offshore chemicals, Port Harcourt, Nigeria.

\section{Biodegradability test}

\section{Biodegradation test procedure}

One Thousand Five hundred milliliter $(1500 \mathrm{ml})$ three set each of the marine, brackish and fresh water sample were dispensed into nine2000ml (2 Litre) Erlenmeyer flask. After that, $1 \%(15 \mathrm{ml})$ each of the different test Industrial detergent: Teepol and Gamazyme were dispensed into the two (2) separate flasks each for the different water (freshwater, brackish and marine). The third $\left(3^{\text {th }}\right)$ flask (that is, 3 separate controls for freshwater, brackish and marine) was not contaminated with any test toxicant and was used as a control (Table 1). The flasks were perforatedlypluged to allow for aeration, and were kept at ambient temperature $\left(28 \pm 2^{0} \mathrm{C}\right)$ for 20 days.

Table 1. Biodegradation set-up.

\begin{tabular}{lll}
\hline Flask 1 $(\boldsymbol{M W}+\boldsymbol{T P})$ & Flask 2(MW+GA) & Flask 3(Control MW) \\
\hline 1500ml Marine water $+1 \%(15 \mathrm{ml})$ Teepol & $1500 \mathrm{ml}$ Marine water $+1 \%(15 \mathrm{ml})$ Gamazyme & 1500ml Marine water \\
Flask $4(B W+T P)$ & Flask $5(B W+G A)$ & Flask $6($ Control BW $)$ \\
$1500 \mathrm{ml}$ Brackish water $+1 \%(15 \mathrm{ml})$ Teepol & $1500 \mathrm{ml}$ Brackish water $+1 \%(15 \mathrm{ml})$ Gamazyme \\
Flask $7(F W+T P)$ & Flask $8(F W+G A)$ & Flask $9($ Control FW $)$ \\
$1500 \mathrm{ml}$ Freshwater $+1 \%(15 \mathrm{ml})$ Teepol & $1500 \mathrm{ml}$ Freshwater $+1 \%(15 \mathrm{ml})$ Gamazyme & $1500 \mathrm{ml}$ Freshwater \\
\hline
\end{tabular}

Key: MW = Marine water, $\mathrm{BW}=$ Brackish water, $\mathrm{FW}=$ Freshwater, $\mathrm{TP}=$ Teepol, GA $=$ Gamazyme 
Samples were taken at day $0,5,10,15$, and 20 from the experimental test flasks to determine the $\mathrm{pH}$, Total Dissolved Solids (TDS), Dissolved Oxygen (DO), Biochemical Oxygen Demand (BOD), Chemical Oxygen Demand (COD), Total Heterotrophic Bacterial Counts, Total Fungal Counts, and Total Industrial Detergent Utilizing Bacteria.

Ultimate biodegradation monitoring using the percentage ratio of $B O D$ to $C O D$

The biochemical oxygen demand (BOD) of each biodegradation test set up was monitored (APHA, 1998) at 0 , $5,10,15$, and 20 days. The chemical oxygen demand was determined at day $0,5,10,15$ and 20 . The ultimate biodegradability (Swisher, 1987; Nrior and Odokuma, 2015) also referred to as the percentage of carbon in the material that is potentially mineralizable was calculated from the percentage of the ratio of BOD (for day $0,5,10,15$, and 20) to $\mathrm{COD}$ at day 0 . The percentage of mineralizable carbon in the test compounds that was actually mineralized was derived from this formula,

$$
\frac{P}{I} \times 100=\mathrm{M}
$$

$100-\mathrm{M}=\mathrm{N}$

$\mathrm{P}=$ percentage of potentially mineralizable carbon in the test compound

$\mathrm{I}=$ percentage of potentially mineralizable carbon in the test compound at day 0

$\mathrm{N}=$ percentage of potentially mineralizable carbon in test compound that was actually mineralized.

\section{Result}

Physical and chemical parameters of freshwater, brackish and marine water samples

The value of some physical and chemical properties of the three aquatic environments used for the study was presented in Table 2. The general appearance of the water were clear, odour of fresh water is unobjectionable while Brackish and marine water have objectionable sensory evaluation. From fresh to marine water; colour decreases from 20.0 to 1.0 Hazen, $\mathrm{pH}$ increased/ranges from 7.67 to 8.21 , Electrical conductivity (EC) ranges from 20 to $9200 \mu \mathrm{S} / \mathrm{cm}$. Turbidity ranges from $<1.0$ to $2.0 \mathrm{NTU}$ with marine water having the lowest and brackish water the highest. Total hardness ranges from 30.70 to $3456.00 \mathrm{mg} / \mathrm{L}$, Total alkalinity $(22.0-$ $142.95 \mathrm{mg} / \mathrm{L})$, Chloride $(28.0$ - $3488.0 \mathrm{mg} / \mathrm{L})$. Total Dissolved Solids followed a similar pattern ranging from 10.0 to $7400.0 \mathrm{mg} / \mathrm{L}$, Total Solids ranged from 18.5 to 7435.0 $\mathrm{mg} / \mathrm{L}$ but Total Suspended Solids ranged from 8.5 to 44.5 $\mathrm{mg} / \mathrm{L}$ with brackish water having the highest value, fresh water the lowest. The value of other parameters in fresh, brackish and marine water were as follows: Nitrate (2.30, 1.65 and $1.90 \mathrm{mg} / \mathrm{L})$, Sulphate $(9.80,2.50$ and $998.50 \mathrm{mg} / \mathrm{L})$, Calcium (7.75, 384.00 and $1152.00 \mathrm{mg} / \mathrm{L})$, Magnesium (1.40, 234.00 and $140.50 \mathrm{mg} / \mathrm{L})$. Biochemical Oxygen Demand (BOD) and Chemical Oxygen Demand (COD) did not reflect this pattern; rather brackish water shows the highest value.

Table 2. Physical and chemical characteristics of the freshwater, brackish and marine water samples.

\begin{tabular}{|c|c|c|c|c|c|}
\hline $\mathbf{S} / \mathbf{N}$ & Physico-chemical characteristics & Unit & Fresh water & Brackish water & Marine water \\
\hline 1 & General Appearance & - & Clear & Clear & Clear \\
\hline 2 & Odour & - & unobjectionable & Objectionable & Objectionable \\
\hline 3 & Colour & Hazen & 20.00 & 10.00 & 1.00 \\
\hline 4 & $\mathrm{pH}$ & - & 7.67 & 7.96 & 8.21 \\
\hline 5 & Electrical Conductivity (EC) & $\mu \mathrm{S} / \mathrm{cm}$ & 20.00 & 7380.00 & 9200.00 \\
\hline 6 & Turbidity & NTU & 1.00 & 2.00 & $<1.00$ \\
\hline 7 & Total Hardness & $\mathrm{mg} / \mathrm{L}$ & 30.70 & 1920.00 & 3456.00 \\
\hline 8 & Total Alkalinity & $\mathrm{mg} / \mathrm{L}$ & 22.00 & 80.55 & 142.95 \\
\hline 9 & Chloride & $\mathrm{mg} / \mathrm{L}$ & 28.00 & 1568.55 & 3488.00 \\
\hline 10 & Total Suspended Solids (TSS) & $\mathrm{mg} / \mathrm{L}$ & 8.50 & 44.50 & 35.10 \\
\hline 11 & Total Dissolved Solids (TDS) & $\mathrm{mg} / \mathrm{L}$ & 10.00 & 6960.00 & 7400.00 \\
\hline 12 & Total Solids & $\mathrm{mg} / \mathrm{L}$ & 18.50 & 7004.50 & 7435.00 \\
\hline 13 & Nitrate & $\mathrm{mg} / \mathrm{L}$ & 2.30 & 1.65 & 1.90 \\
\hline 14 & Sulphate & $\mathrm{mg} / \mathrm{L}$ & 9.80 & 2.50 & 998.50 \\
\hline 15 & Calcium & $\mathrm{mg} / \mathrm{L}$ & 7.75 & 384.00 & 1152.00 \\
\hline 16 & Magnesium & $\mathrm{mg} / \mathrm{L}$ & 1.40 & 234.20 & 140.50 \\
\hline 17 & Biochemical Oxygen Demand (BOD) & $\mathrm{mg} / \mathrm{L}$ & 21.90 & 27.90 & 9.10 \\
\hline 18 & Chemical Oxygen Demand (COD) & $\mathrm{mg} / \mathrm{L}$ & 52.60 & 66.90 & 48.1 \\
\hline 19 & Total Iron $(\mathrm{Fe})$ & $\mathrm{mg} / \mathrm{L}$ & 0.65 & 0.21 & 0.81 \\
\hline 20 & Lead $(\mathrm{Pb})$ & $\mathrm{mg} / \mathrm{L}$ & $<0.001$ & 0.07 & $<0.001$ \\
\hline 21 & Copper $(\mathrm{Cu})$ & $\mathrm{mg} / \mathrm{L}$ & 0.001 & $<0.001$ & 0.02 \\
\hline
\end{tabular}

Comparative evaluation of changes in value of physicochemical and microbiological parameters during biodegradation of petroleum products in freshwater, brackish and marine water

The comparative evaluation of the physico-chemistry and microbiological parameters of the biodegradation set-up for the different water (fresh, brackish and marine) samples spiked with the different industrial detergents were taken for Day 1, 5, 10, 15, 20. The values of the physico-chemical parameters: Hydrogen ion concentration [pH], Total Dissolved Solids [TDS], Dissolved Oxygen [DO], Biochemical Oxygen Demand [BOD], Chemical Oxygen 
Demand [COD], Ultimate Biodegradability from percentage ratio of Biochemical Oxygen Demand to Chemical Oxygen Demand taken during biodegradation of Industrial detergent;
Teepol and Gamazyme) in fresh, brackish and marine water were shown in Table $3-9$ respectively.

Table 3. Changes in Hydrogen ion concentration $(p H)$ levels during Biodegradation Industrial detergent; Teepol and Gamazyme.

\begin{tabular}{|c|c|c|c|c|c|c|c|c|c|}
\hline Day & $\begin{array}{l}\text { Fresh water } \\
\text { control }\end{array}$ & $\begin{array}{l}\text { Fresh water } \\
\text { +Teepol }\end{array}$ & $\begin{array}{l}\text { Fresh water } \\
\text { +Gamazyme }\end{array}$ & $\begin{array}{l}\text { Brackish } \\
\text { Water control } \\
\end{array}$ & $\begin{array}{l}\text { Brackish water } \\
\text { +Teepol }\end{array}$ & $\begin{array}{l}\text { Brackish water } \\
\text { +Gamazyme }\end{array}$ & $\begin{array}{l}\text { Marine Water } \\
\text { control }\end{array}$ & $\begin{array}{l}\text { Marine water } \\
\text { +Teepol }\end{array}$ & $\begin{array}{l}\text { Marine water } \\
\text { +Gamazyme }\end{array}$ \\
\hline 0 & 6.84 & 7.47 & 7.83 & 8.08 & 7.63 & 7.43 & 7.84 & 7.44 & 7.35 \\
\hline 5 & 7.83 & 7.72 & 7.60 & 8.05 & 8.20 & 7.81 & 8.02 & 8.22 & 8.07 \\
\hline 10 & 7.98 & 7.89 & 7.60 & 7.97 & 7.91 & 7.85 & 8.06 & 7.96 & 7.61 \\
\hline 15 & 7.90 & 7.87 & 7.37 & 7.89 & 8.15 & 7.54 & 8.90 & 7.82 & 7.96 \\
\hline 20 & 7.78 & 7.32 & 7.06 & 7.80 & 8.03 & 7.43 & 8.24 & 8.12 & 8.05 \\
\hline
\end{tabular}

Table 4. Changes in Total Dissolved Solids (TDS) levels during Biodegradation Industrial detergent; Teepol and Gamazyme.

\begin{tabular}{|c|c|c|c|c|c|c|c|c|c|}
\hline Day & $\begin{array}{l}\text { Fresh water } \\
\text { control }\end{array}$ & $\begin{array}{l}\text { Fresh water } \\
\text { +Teepol }\end{array}$ & $\begin{array}{l}\text { Fresh water } \\
\text { +Gamazyme }\end{array}$ & $\begin{array}{l}\text { Brackish } \\
\text { Water control } \\
\end{array}$ & $\begin{array}{l}\text { Brackish water } \\
\text { +Teepol }\end{array}$ & $\begin{array}{l}\text { Brackish water } \\
\text { +Gamazyme }\end{array}$ & $\begin{array}{l}\text { Marine Water } \\
\text { control }\end{array}$ & $\begin{array}{l}\text { Marine water } \\
\text { +Teepol }\end{array}$ & $\begin{array}{l}\text { Marine water } \\
\text { +Gamazyme }\end{array}$ \\
\hline & $\mathrm{mg} / \mathrm{l}$ & $\mathrm{mg} / \mathrm{l}$ & $\mathrm{mg} / \mathrm{l}$ & $m g / l$ & $m g / l$ & $m g / l$ & $m g / l$ & $m g / l$ & $m g / l$ \\
\hline 0 & 192 & 233 & 162 & 1850 & 1920 & 1840 & 2500 & 2650 & 2540 \\
\hline 5 & 92 & 237 & 82 & 2370 & 2190 & 2390 & 2740 & 2490 & 2670 \\
\hline 10 & 105 & 263 & 90 & 2060 & 2170 & 2200 & 2030 & 2600 & 2580 \\
\hline 15 & 121 & 257 & 103 & 2030 & 2110 & 2010 & 5330 & 3930 & 2900 \\
\hline 20 & 135 & 288 & 127 & 1770 & 1790 & 1740 & 7920 & 8310 & 8520 \\
\hline
\end{tabular}

Table 5. Changes in Dissolved Oxygen (DO) levels during Biodegradation Industrial detergent; Teepol and Gamazyme.

\begin{tabular}{|c|c|c|c|c|c|c|c|c|c|}
\hline Day & $\begin{array}{l}\text { Fresh water } \\
\text { control }\end{array}$ & $\begin{array}{l}\text { Fresh water } \\
\text { +Teepol }\end{array}$ & $\begin{array}{l}\text { Fresh water } \\
\text { +Gamazyme }\end{array}$ & $\begin{array}{l}\text { Brackish } \\
\text { Water control }\end{array}$ & $\begin{array}{l}\text { Brackish water } \\
\text { +Teepol }\end{array}$ & $\begin{array}{l}\text { Brackish water } \\
\text { +Gamazyme }\end{array}$ & $\begin{array}{l}\text { Marine Water } \\
\text { control }\end{array}$ & $\begin{array}{l}\text { Marine water } \\
\text { +Teepol }\end{array}$ & $\begin{array}{l}\text { Marine water } \\
\text { +Gamazyme }\end{array}$ \\
\hline & $\mathrm{mg} / \mathrm{l}$ & $\mathrm{mg} / \mathrm{l}$ & $\mathrm{mg} / \mathrm{l}$ & $m g / l$ & $m g / l$ & $m g / l$ & $m g / l$ & $m g / l$ & $m g / l$ \\
\hline 0 & 10.2 & 9.4 & 9.0 & 10.3 & 15.7 & 13.3 & 5.2 & 4.1 & 4.5 \\
\hline 5 & 8.6 & 7.0 & 6.7 & 9.2 & 9.1 & 9.8 & 4.4 & 4.6 & 4.5 \\
\hline 10 & 7.0 & 7.0 & 6.7 & 7.9 & 7.9 & 7.8 & 4.3 & 5.8 & 5.3 \\
\hline 15 & 6.5 & 6.2 & 6.4 & 4.5 & 4.6 & 4.6 & 3.9 & 5.3 & 4.8 \\
\hline 20 & 6.4 & 5.0 & 6.2 & 4.2 & 4.5 & 3.6 & 1.9 & 2.6 & 2.9 \\
\hline
\end{tabular}

Table 6. Changes in Biochemical Oxygen Demand (BOD) levels during Biodegradation Industrial detergent-T-pol.

\begin{tabular}{|c|c|c|c|c|c|c|c|c|c|}
\hline Day & $\begin{array}{l}\text { Fresh water } \\
\text { control }\end{array}$ & $\begin{array}{l}\text { Fresh water } \\
\text { +Teepol }\end{array}$ & $\begin{array}{l}\text { Fresh water } \\
\text { +Gamazyme }\end{array}$ & $\begin{array}{l}\text { Brackish } \\
\text { Water control }\end{array}$ & $\begin{array}{l}\text { Brackish water } \\
\text { +Teepol }\end{array}$ & $\begin{array}{l}\text { Brackish water } \\
\text { +Gamazyme }\end{array}$ & $\begin{array}{l}\text { Marine Water } \\
\text { control }\end{array}$ & $\begin{array}{l}\text { Marine water } \\
+ \text { Teepol }\end{array}$ & $\begin{array}{l}\text { Marine water } \\
\text { +Gamazyme }\end{array}$ \\
\hline & $\mathrm{mg} / \mathrm{l}$ & $\mathrm{mg} / \mathrm{l}$ & $\mathrm{mg} / \mathrm{l}$ & $m g / l$ & $m g / l$ & $m g / l$ & $m g / l$ & $\mathrm{mg} / \mathrm{l}$ & $m g / l$ \\
\hline 0 & 27.6 & 25.4 & 24.4 & 27.9 & 42.5 & 36.0 & 14.1 & 11.1 & 12.2 \\
\hline 5 & 23.3 & 18.9 & 18.1 & 24.9 & 24.6 & 26.5 & 11.9 & 12.5 & 12.2 \\
\hline 10 & 18.9 & 18.9 & 18.1 & 21.4 & 21.4 & 21.1 & 11.6 & 15.7 & 14.3 \\
\hline 15 & 17.6 & 16.8 & 17.3 & 12.2 & 12.5 & 12.5 & 10.6 & 14.3 & 13.0 \\
\hline 20 & 17.3 & 13.5 & 16.8 & 11.4 & 12.2 & 9.7 & 5.1 & 7.0 & 7.9 \\
\hline
\end{tabular}

Table 7. Changes in Chemical Oxygen Demand (COD) levels during Biodegradation of Industrial detergent; Teepol and Gamazyne.

\begin{tabular}{|c|c|c|c|c|c|c|c|c|c|}
\hline Day & $\begin{array}{l}\text { Fresh water } \\
\text { control }\end{array}$ & $\begin{array}{l}\text { Fresh water } \\
\text { +Teepol }\end{array}$ & $\begin{array}{l}\text { Fresh water } \\
\text { +Gamazyme }\end{array}$ & $\begin{array}{l}\text { Brackish Water } \\
\text { control }\end{array}$ & $\begin{array}{l}\text { Brackish water } \\
\text { +Teepol }\end{array}$ & $\begin{array}{l}\text { Brackish water } \\
\text { +Gamazyme }\end{array}$ & $\begin{array}{l}\text { Marine Water } \\
\text { control }\end{array}$ & $\begin{array}{l}\text { Marine water } \\
\text { +Teepol }\end{array}$ & $\begin{array}{l}\text { Marine water } \\
\text { +Gamazyme }\end{array}$ \\
\hline & $\mathrm{mg} / \mathrm{l}$ & $\mathrm{mg} / \mathrm{l}$ & $\mathrm{mg} / \mathrm{l}$ & $m g / l$ & $m g / l$ & $m g / l$ & $m g / l$ & $m g / l$ & $m g / l$ \\
\hline 0 & 66.5 & 122.1 & 116.9 & 67.0 & 204.0 & 172.8 & 34.0 & 53.3 & 58.5 \\
\hline 5 & 56.0 & 90.9 & 87.1 & 60.0 & 118.2 & 127.3 & 28.5 & 59.8 & 58.5 \\
\hline 10 & 45.5 & 90.9 & 87.1 & 51.5 & 102.6 & 101.3 & 28.0 & 75.4 & 68.9 \\
\hline 15 & 42.5 & 80.6 & 83.2 & 29.5 & 59.8 & 59.8 & 25.5 & 68.9 & 62.4 \\
\hline 20 & 41.5 & 65.0 & 80.6 & 27.5 & 58.5 & 58.5 & 12.5 & 33.8 & 37.7 \\
\hline
\end{tabular}

Table 8. Percentage (\%) carbon in Industrial detergent - T-pol that is mineralizable.

\begin{tabular}{|c|c|c|c|c|c|c|c|c|c|}
\hline Day & $\begin{array}{l}\text { Fresh water } \\
\text { control }\end{array}$ & $\begin{array}{l}\text { Fresh water } \\
+ \text { T-pol }\end{array}$ & $\begin{array}{l}\text { Fresh water } \\
\text { +Gamazyme }\end{array}$ & $\begin{array}{l}\text { Brackish Water } \\
\text { control }\end{array}$ & $\begin{array}{l}\text { Brackish water } \\
+ \text { T-pol }\end{array}$ & $\begin{array}{l}\text { Brackish water } \\
\text { +Gamazyme }\end{array}$ & $\begin{array}{l}\text { Marine Water } \\
\text { control }\end{array}$ & $\begin{array}{l}\text { Marine } \\
\text { water +T-pol }\end{array}$ & $\begin{array}{l}\text { Marine water } \\
\text { +Gamazyme }\end{array}$ \\
\hline & $\%$ & $\%$ & $\%$ & $\%$ & $\%$ & $\%$ & $\%$ & $\%$ & $\%$ \\
\hline 0 & 41.5 & 20.80 & 20.87 & 41.6 & 20.83 & 20.83 & 41.5 & 20.83 & 20.85 \\
\hline 5 & 35.0 & 15.48 & 15.48 & 37.2 & 12.06 & 15.34 & 35.0 & 23.45 & 20.85 \\
\hline 10 & 28.4 & 15.48 & 15.48 & 31.9 & 10.49 & 12.21 & 34.1 & 29.46 & 24.44 \\
\hline 15 & 26.5 & 13.76 & 14.80 & 18.2 & 6.13 & 7.23 & 31.2 & 26.83 & 22.22 \\
\hline 20 & 26 & 11.06 & 14.37 & 17.0 & 5.98 & 5.61 & 15.0 & 13.13 & 13.50 \\
\hline
\end{tabular}


Table 9. Percentage (\%) Ultimate Biodegradation (potentially mineralizable carbon) in industrial detergent-T-pol.

\begin{tabular}{|c|c|c|c|c|c|c|c|c|c|}
\hline Day & $\begin{array}{l}\text { Fresh water } \\
\text { control }\end{array}$ & $\begin{array}{l}\text { Fresh water } \\
+ \text { T-pol }\end{array}$ & $\begin{array}{l}\text { Fresh water } \\
\text { +Gamazyme }\end{array}$ & $\begin{array}{l}\text { Brackish } \\
\text { water control }\end{array}$ & $\begin{array}{l}\text { Brackish water } \\
+ \text { T-pol }\end{array}$ & $\begin{array}{l}\text { Brackish water } \\
\text { +Gamazyme }\end{array}$ & $\begin{array}{l}\text { Marine Water } \\
\text { control }\end{array}$ & $\begin{array}{l}\text { Marine water } \\
+\mathrm{T} \text {-pol }\end{array}$ & $\begin{array}{l}\text { Marine water } \\
\text { +Gamazyme }\end{array}$ \\
\hline & $\%$ & $\%$ & $\%$ & $\%$ & $\%$ & $\%$ & $\%$ & $\%$ & $\%$ \\
\hline 0 & 0 & 0 & 0 & 0 & 0 & 0 & 0 & 0 & 0 \\
\hline 5 & 15.7 & 25.5 & 25.8 & 10.6 & 41.8 & 26.4 & 15.8 & 10.2 & 9 \\
\hline 10 & 31.6 & 25.5 & 25.8 & 23.4 & 49.5 & 41.3 & 17.8 & 20.3 & 14.3 \\
\hline 15 & 36.2 & 33.7 & 29.2 & 56.2 & 70.7 & 65.4 & 24.8 & 29.5 & 14.3 \\
\hline 20 & 37.4 & 46.6 & 31.1 & 59.2 & 71.2 & 73.1 & 63.0 & 55.6 & 44.7 \\
\hline
\end{tabular}

Table 10. Changes in count of Heterotrophic Bacteria (log10 cfu/ml) during Biodegradation Industrial detergent - T-pol.

\begin{tabular}{|c|c|c|c|c|c|c|c|c|c|}
\hline Day & $\begin{array}{l}\text { Fresh water } \\
\text { control } \\
\end{array}$ & $\begin{array}{l}\text { Fresh water } \\
+ \text { T-pol } \\
\end{array}$ & $\begin{array}{l}\text { Fresh water } \\
\text { +Gamazyme }\end{array}$ & $\begin{array}{l}\text { Brackish Water } \\
\text { control }\end{array}$ & $\begin{array}{l}\text { Brackish water } \\
+ \text { T-pol }\end{array}$ & $\begin{array}{l}\text { Brackish water } \\
\text { +Gamazyme }\end{array}$ & $\begin{array}{l}\text { Marine Water } \\
\text { control }\end{array}$ & $\begin{array}{l}\text { Marine } \\
\text { water +T-pol } \\
\end{array}$ & $\begin{array}{l}\text { Marine water } \\
\text { +Gamazyme }\end{array}$ \\
\hline & $\log 10 c f u / m l$ & $\log 10 c f u / m l$ & $\log 10 c f u / m l$ & $\log 10 c f u / m l$ & $\log 10 \mathrm{cfu} / \mathrm{ml}$ & $\log 10 c f u / m l$ & $\log 10 c f u / m l$ & $\log 10 c f u / m l$ & $\log 10 c f u / m l$ \\
\hline 0 & 6.48 & 7.08 & 6.97 & 6.70 & 6.79 & 6.77 & 5.18 & 7.15 & 7.85 \\
\hline 5 & 6.46 & 6.66 & 6.9 & 6.54 & 6.85 & 6.78 & 5.85 & 5.7 & 4.3 \\
\hline 10 & 6.57 & 6.6 & 6.78 & 6.30 & 6.8 & 6.79 & 5.84 & 6.78 & 5.18 \\
\hline 15 & 6.18 & 6.38 & 4.7 & 6.30 & 6.38 & 6.48 & 5.3 & 6.9 & 5.36 \\
\hline 20 & 6.15 & 6.3 & 5.26 & 6.18 & 6.38 & 6.6 & 5.2 & 4.95 & 3.66 \\
\hline
\end{tabular}

Table 11. Changes in count of Fungi (log10 cfu/ml) during Biodegradation Industrial detergent; Teepol and Gamazyme.

\begin{tabular}{|c|c|c|c|c|c|c|c|c|c|}
\hline Day & $\begin{array}{l}\text { Fresh water } \\
\text { control }\end{array}$ & $\begin{array}{l}\text { Fresh water } \\
+ \text { T-pol }\end{array}$ & $\begin{array}{l}\text { Fresh water } \\
\text { +Gamazyme }\end{array}$ & $\begin{array}{l}\text { Brackish Water } \\
\text { control }\end{array}$ & $\begin{array}{l}\text { Brackish water } \\
+ \text { T-pol }\end{array}$ & $\begin{array}{l}\text { Brackish water } \\
\text { +Gamazyme }\end{array}$ & $\begin{array}{l}\text { Marine Water } \\
\text { control }\end{array}$ & $\begin{array}{l}\text { Marine } \\
\text { water +T-pol }\end{array}$ & $\begin{array}{l}\text { Marine water } \\
\text { +Gamazyme }\end{array}$ \\
\hline & $\log 10 c f u / m l$ & $\log 10 c f u / m l$ & $\log 10 c f u / m l$ & $\log 10 c f u / m l$ & $\log 10 c f u / m l$ & $\log 10 c f u / m l$ & $\log 10 c f u / m l$ & $\log 10 c f u / m l$ & $\log 10 c f u / m l$ \\
\hline 0 & 4.45 & 4.18 & 4.45 & 4.6 & 5.0 & 3.3 & 4.48 & 3.86 & 3.95 \\
\hline 5 & 2.95 & 3.0 & 3.0 & 4.48 & 5.0 & 3.4 & 4.0 & 3.6 & 3.78 \\
\hline 10 & 3.7 & 4.4 & 3.18 & 4.3 & 4.6 & 4.62 & 3.85 & 3.78 & 4.08 \\
\hline 15 & 3.6 & 4.3 & 3.15 & 4.18 & 4.68 & 3.3 & 3.7 & 4.0 & 4.18 \\
\hline 20 & 3.65 & 4.15 & 3.18 & 4.0 & 4.3 & 3.0 & 3.48 & 3.6 & 3.28 \\
\hline
\end{tabular}

Table 12. Changes in count of Industrial Detergent Utilizing Bacteria (IDUB -log10 cfu/ml) during Biodegradation of Industrial detergent-T-pol.

\begin{tabular}{|c|c|c|c|c|c|c|c|c|c|}
\hline \multirow[t]{2}{*}{ Day } & $\begin{array}{l}\text { Fresh water } \\
\text { control }\end{array}$ & $\begin{array}{l}\text { Fresh water } \\
+ \text { T-pol }\end{array}$ & $\begin{array}{l}\text { Fresh water } \\
\text { +Gamazyme }\end{array}$ & $\begin{array}{l}\text { Brackish Water } \\
\text { control }\end{array}$ & $\begin{array}{l}\text { Brackish } \\
\text { water +T-pol }\end{array}$ & $\begin{array}{l}\text { Brackish water } \\
\text { +Gamazyme }\end{array}$ & $\begin{array}{l}\text { Marine Water } \\
\text { control }\end{array}$ & $\begin{array}{l}\text { Marine water } \\
+ \text { T-pol }\end{array}$ & $\begin{array}{l}\text { Marine water } \\
\text { +Gamazyme }\end{array}$ \\
\hline & $\log 10 c f u / m l$ & $\log 10 c f u / m l$ & $\log 10 c f u / m l$ & $\log 10 c f u / m l$ & $\log 10 c f u / m l$ & $\log 10 c f u / m l$ & $\log 10 c f u / m l$ & $\log 10 c f u / m l$ & $\log 10 c f u / m l$ \\
\hline 0 & 2.6 & 3.82 & 3.48 & 4.48 & 4.2 & 4.3 & 3.6 & 3.78 & 3.7 \\
\hline 5 & 2.3 & 3.81 & 3.4 & 4.0 & 4.18 & 4.26 & 2.3 & 3.9 & 3.7 \\
\hline 10 & 2.48 & 3.89 & 2.7 & 3.85 & 4.3 & 4.0 & 2.48 & 4.0 & 3.95 \\
\hline 15 & 2.3 & 3.88 & 2.6 & 3.7 & 4.3 & 3.95 & 2.48 & 4.26 & 4.08 \\
\hline 20 & 2.0 & 3.86 & 2.48 & 3.48 & 4.23 & 3.7 & 2.48 & 3.34 & 3.2 \\
\hline
\end{tabular}

Table 13. Changes in Physico-chemical and microbiological parameters during Biodegradation Industrial detergent T-pol in marine, brackish and freshwater ecosystems.

\begin{tabular}{|c|c|c|c|c|}
\hline Parameter & Fresh water control & Fresh water $+\mathbf{T}$-pol & Fresh water +Gamazyme & Brackish Water control \\
\hline $\mathrm{pH}$ & $7.67 \pm 0.47$ & $7.65 \pm 0.25$ & $7.49 \pm 0.32$ & $7.96 \pm 0.12$ \\
\hline TDS (mg/L) & $129 \pm 38.77$ & $256 \pm 0.30$ & $113 \pm 32.35$ & $2016 \pm 232.12$ \\
\hline $\mathrm{DO}(\mathrm{mg} / \mathrm{L})$ & $7.7 \pm 1.63$ & $6.9 \pm 1.61$ & $7.0 \pm 1.14$ & $7.2 \pm 2.76$ \\
\hline $\mathrm{BOD}(\mathrm{mg} / \mathrm{L})$ & $20.94 \pm 4.43$ & $18.70 \pm 4.35$ & $18.94 \pm 3.10$ & $19.56 \pm 7.47$ \\
\hline $\mathrm{COD}(\mathrm{mg} / \mathrm{L})$ & $50.4 \pm 10.68$ & $89.90 \pm 20.89$ & $90.88 \pm 14.75$ & $47.1 \pm 17.86$ \\
\hline$\%$ Ultimate Biodegrad. & $24.18 \pm 16.05$ & $26.26 \pm 17.03$ & $22.38 \pm 12.72$ & $29.88 \pm 26.73$ \\
\hline THB & $6.37 \pm 0.19$ & $6.60 \pm 0.31$ & $6.12 \pm 1.06$ & $6.40 \pm 0.21$ \\
\hline Total Fungi & $3.67 \pm 0.53$ & $4.00 \pm 0.57$ & $3.39 \pm 0.60$ & $4.31 \pm 0.24$ \\
\hline IDUB & $2.34 \pm 0.23$ & $3.85 \pm 0.04$ & $2.93 \pm 0.47$ & $3.90 \pm 0.38$ \\
\hline
\end{tabular}


Table 13. Continued.

\begin{tabular}{llllll}
\hline Parameter & $\begin{array}{l}\text { Brackish water +T- } \\
\text { pol }\end{array}$ & $\begin{array}{l}\text { Brackish water } \\
\text { +Gamazyme }\end{array}$ & $\begin{array}{l}\text { Marine Water } \\
\text { control }\end{array}$ & $\begin{array}{l}\text { Marine water +T- } \\
\text { pol }\end{array}$ & $\begin{array}{l}\text { Marine water } \\
\text { +Gamazyme }\end{array}$ \\
\hline pH & $7.98 \pm 0.23$ & $7.61 \pm 0.20$ & $8.21 \pm 0.41$ & $7.91 \pm 0.30$ & $7.81 \pm 0.31$ \\
TDS $(\mathrm{mg} / \mathrm{L})$ & $2036 \pm 174.01$ & $2036 \pm 264.06$ & $4104 \pm 2489.97$ & $3996 \pm 2482.11$ & $3842 \pm 2618.80$ \\
DO $(\mathrm{mg} / \mathrm{L})$ & $8.4 \pm 4.57$ & $7.8 \pm 3.94$ & $3.9 \pm 1.23$ & $4.5 \pm 1.24$ & $4.4 \pm 0.90$ \\
BOD $(\mathrm{mg} / \mathrm{L})$ & $22.64 \pm 12.37$ & $21.16 \pm 10.67$ & $10.66 \pm 3.36$ & $12.12 \pm 3.35$ & $11.92 \pm 2.41$ \\
COD $(\mathrm{mg} / \mathrm{L})$ & $108.62 \pm 59.42$ & $101.60 \pm 48.24$ & $25.7 \pm 8.00$ & $58.24 \pm 16.06$ & $57.20 \pm 11.70$ \\
\% Carbon minerlizable & $11.10 \pm 6.06$ & $12.24 \pm 6.17$ & $31.36 \pm 9.89$ & $22.74 \pm 6.29$ & $20.37 \pm 4.11$ \\
\% Ultimate Biodegrad. & $46.64 \pm 29.11$ & $41.24 \pm 29.66$ & $24.28 \pm 23.47$ & $23.12 \pm 21.24$ & $16.46 \pm 16.83$ \\
THB & $6.64 \pm 0.24$ & $6.68 \pm 0.14$ & $5.47 \pm 0.34$ & $6.30 \pm 0.93$ & $5.17 \pm 1.60$ \\
Total Fungi & $4.72 \pm 0.30$ & $3.52 \pm 0.63$ & $3.90 \pm 0.38$ & $3.77 \pm 0.17$ & $3.85 \pm 0.35$ \\
IDUB & $4.24 \pm 0.06$ & $4.04 \pm 0.25$ & $2.67 \pm 0.53$ & $3.86 \pm 0.34$ & $3.73 \pm 0.34$ \\
\hline
\end{tabular}

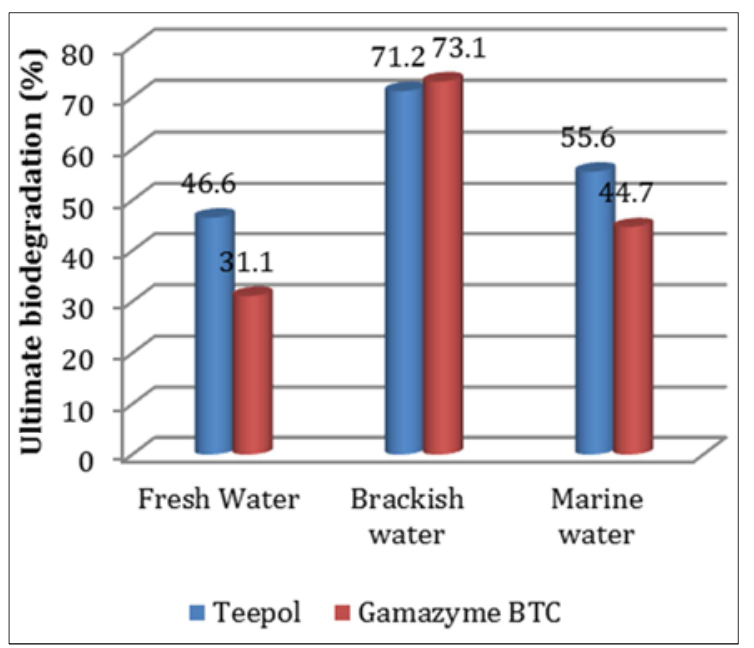

Figure 1. Ultimate biodegradation (\%) of petroleum products in freshwater, brackish and marine water systems at day 20.

The changes in values of microbiological parameters: Total Heterotrophic Bacteria [THB], Total Fungi [TF], Industrial Detergent Utilizing Bacteria [IDUB], taken during Biodegradation of Industrial detergent - Teepol and Gamazyme) for day 0, 5, 10, 15 and 20 in fresh, brackish and marine water were also shown in Table $10-12$.

Comparative evaluation of percentage (\%) ultimate

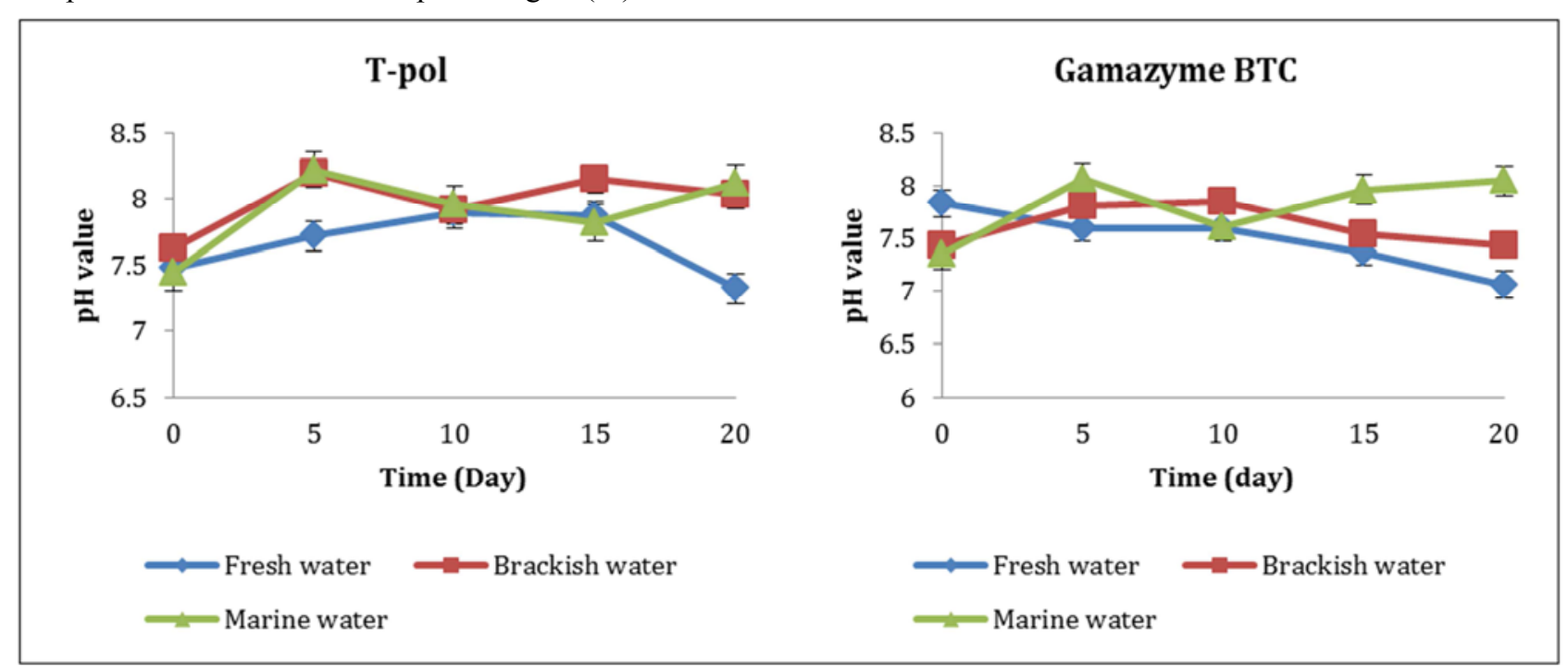

Figure 2. Hydrogen ion concentration $(\mathrm{pH})$ during biodegradation of industrial detergents in fresh, brackish and marine water. biodegradability of petroleum products in freshwater, brackish and marine water

The comparative evaluation of the ultimate biodegradation (\%) of Industrial detergent; Teepol and Gamazyme in fresh, brackish and marine water were shown in figure 1 , value of ultimate biodegradation (\%) of petroleum products were as follows: Freshwater system (ultimate biodegradation - \%): Teepol (46.6) > Gamazyme (31.1); Brackish water system: Gamazyme(73.1) > T-pol (71.2) and Marine water system: Teepol (55.6) > Gamazyme (44.7).

The physico-chemical parameters of individual test industrial detergent: Hydrogen ion concentration $(\mathrm{pH})$, Total Dissolved Solids (TDS), Biochemical Oxygen Demand [BOD], Chemical Oxygen Demand [COD], Ultimate Biodegradability from percentage ratio of Biochemical Oxygen Demand to Chemical Oxygen Demand taken during biodegradation of Industrial detergent; Teepol and Gamazyme for day $0,5,10,15$ and 20 in fresh, brackish and marine water were shown in Figure 2-7 while the values of microbiological parameters: Total Heterotrophic Bacteria [THB], Total Fungi [TF], Industrial Detergent Utilizing Bacteria [IDUB], taken during Biodegradation of Industrial detergent - Teepol and Gamazyme for day 0, 5, 10, 15 and 20 in freshwater, brackish and marine water were also shown in Figure 7-9. 


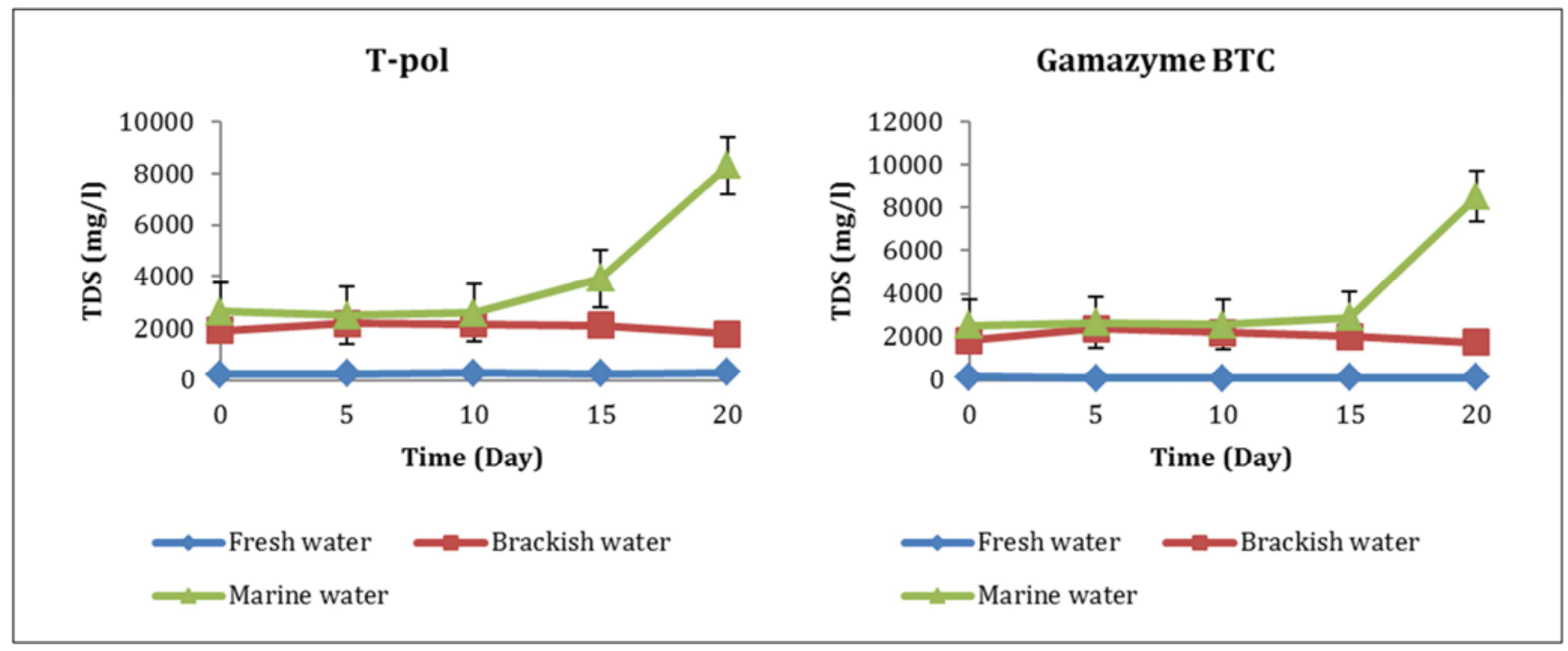

Figure 3. Total Dissolved Solids (TDS - mg/l) during biodegradation of industrial detergents in fresh, brackish and marine water.

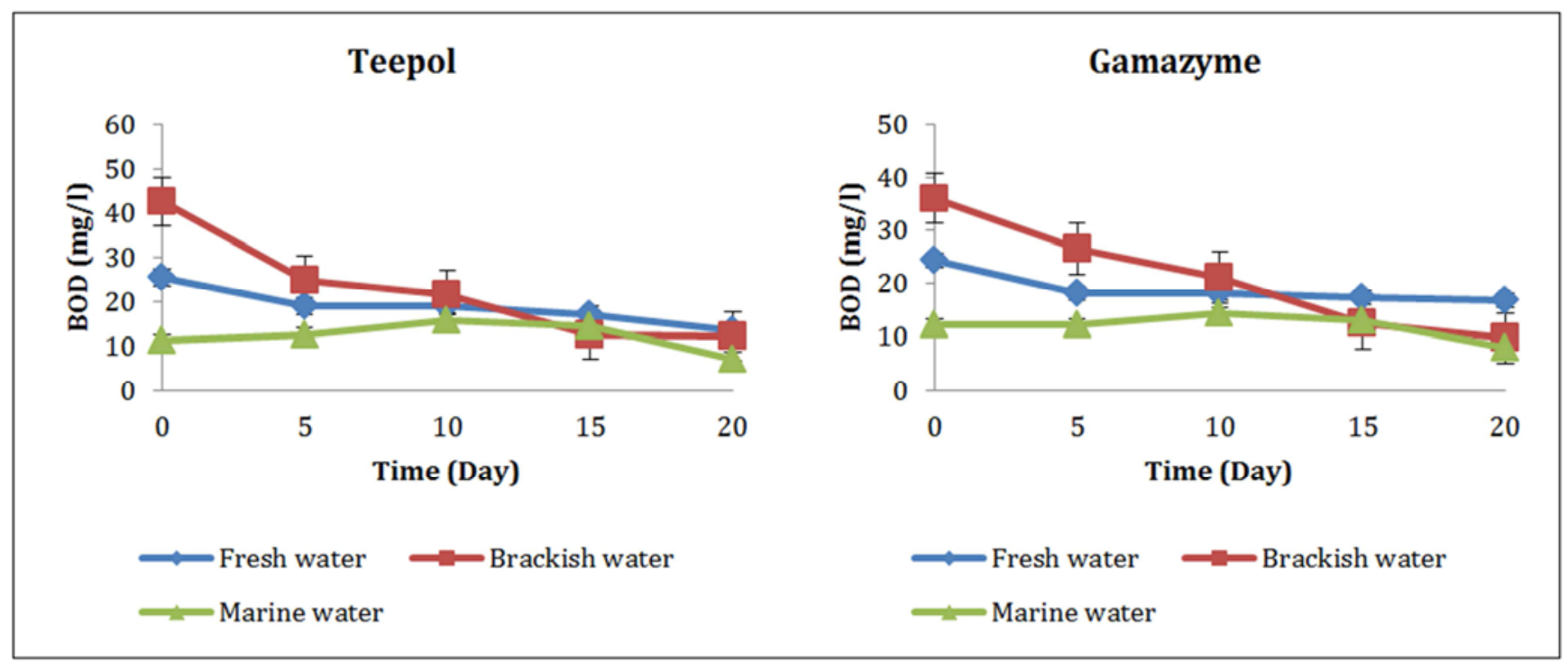

Figure 4. Biochemical Oxygen Demand (BOD - mg/l) during biodegradation of industrial detergents in fresh, brackish and marine water.

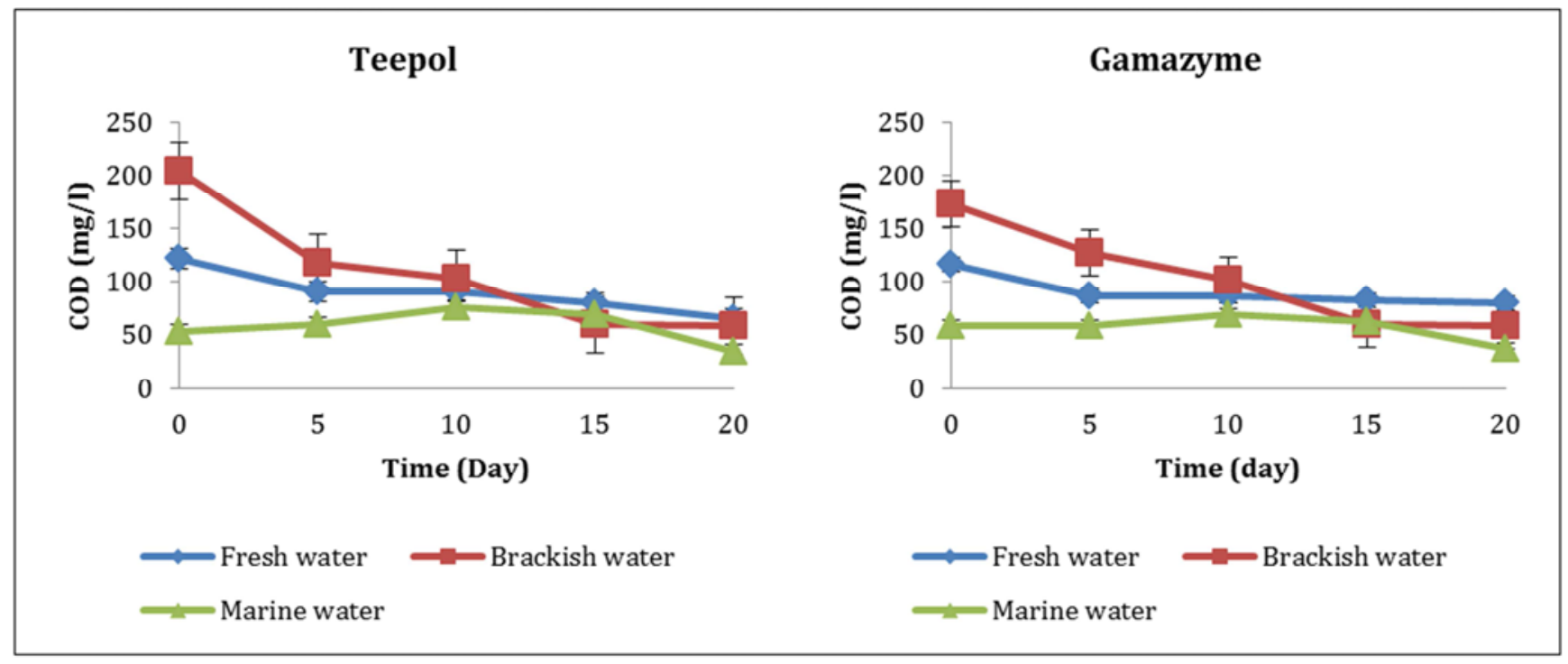

Figure 5. Chemical Oxygen Demand (COD - mg/l) during biodegradation of industrial detergents in fresh, brackish and marine water. 


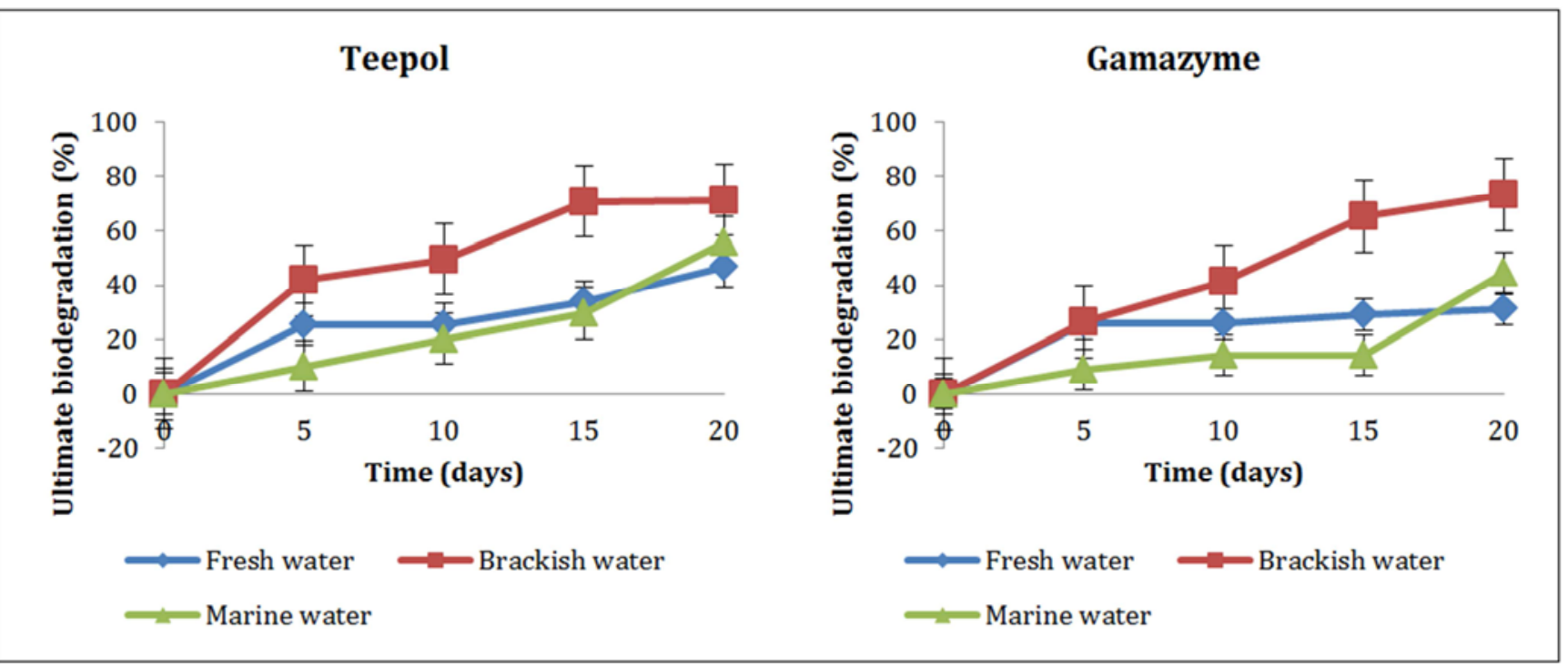

Figure 6. Percentage (\%) Ultimate biodegradation of industrial detergents in freshwater, brackish and marine water.

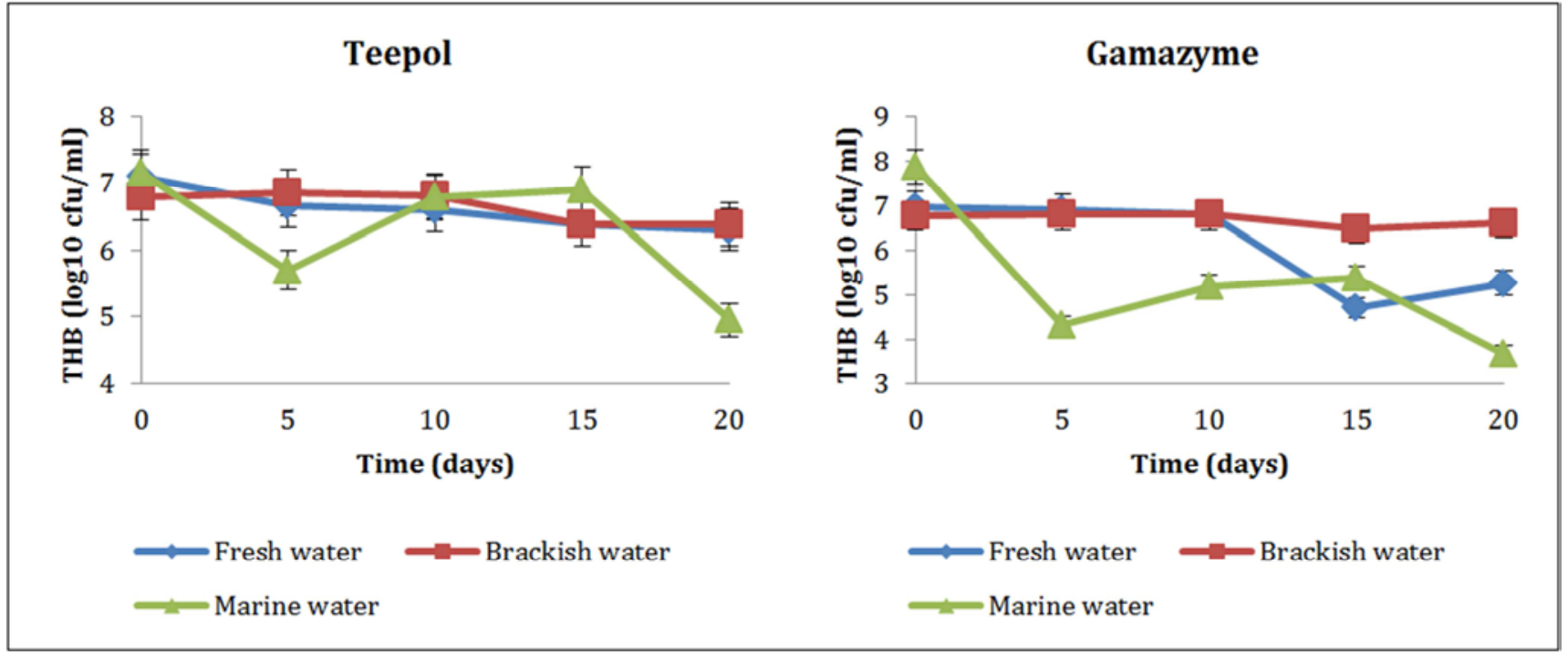

Figure 7. Total Heterotrophic bacteria $(T H B-\log 10 \mathrm{cfu} / \mathrm{ml})$ count of petroleum products in fresh water, brackish and marine water.

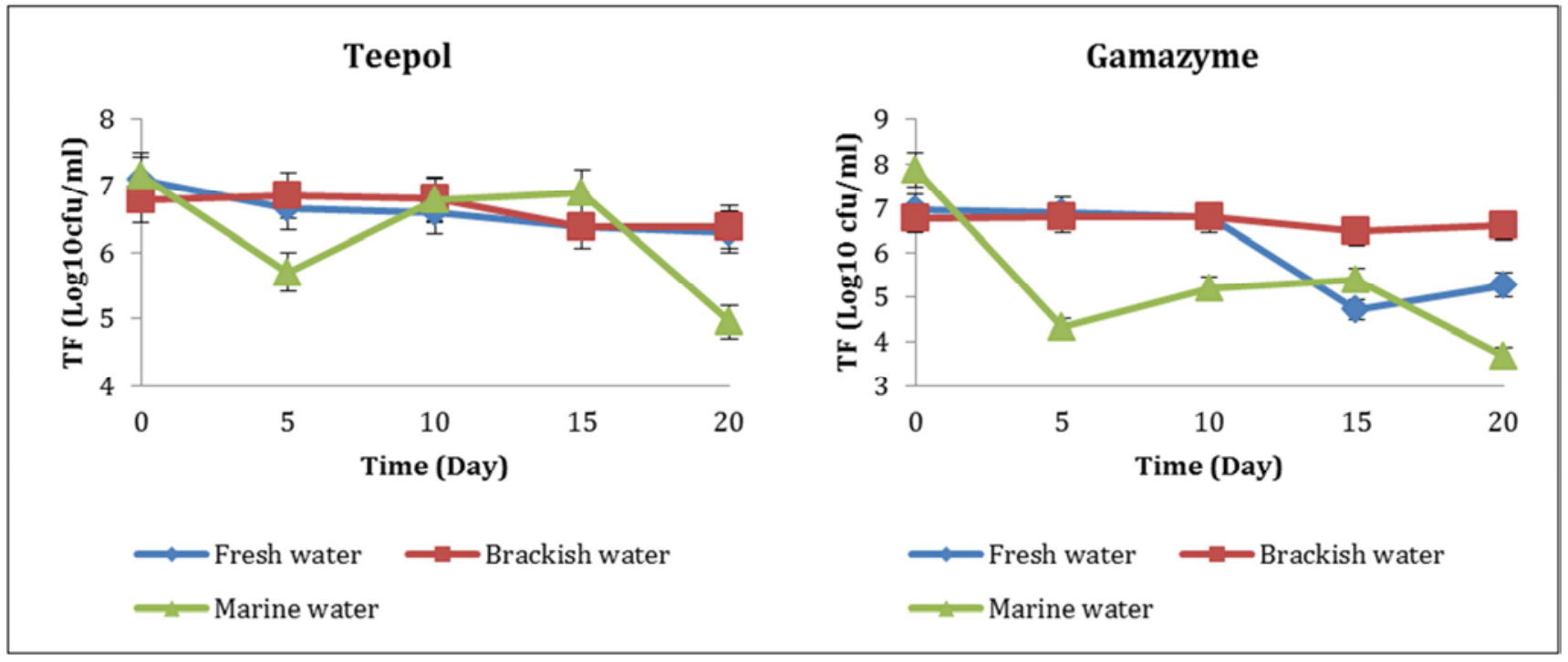

Figure 8. Total fungi (TF - $\log 10 \mathrm{cfu} / \mathrm{ml})$ count of petroleum products in freshwater, brackish and marine water. 


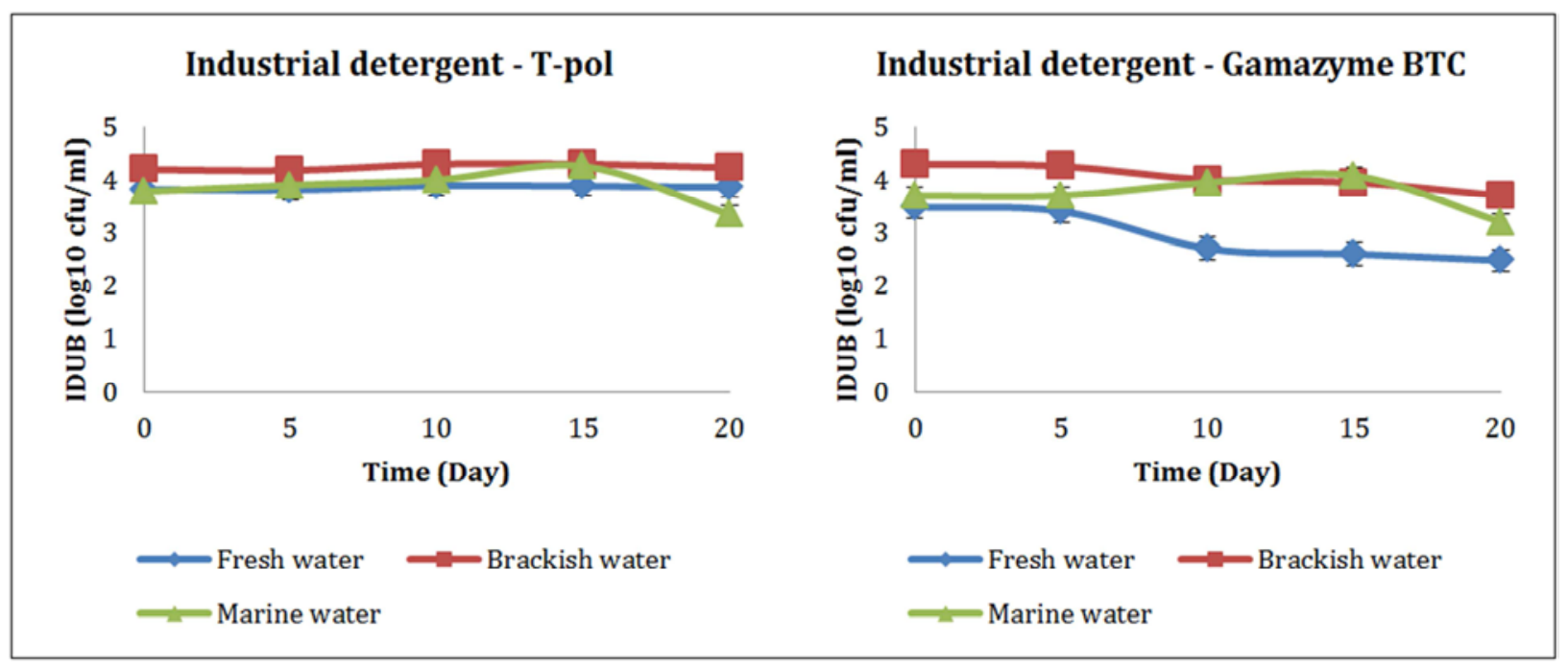

Figure 9. Industrial Detergent Utilizing Bacteria (IDUB - log10 cfu/ml) count of petroleum products in fresh water, brackish and marine water.

Spread plate technique was used to grow culture fungi on Sabouroud dextrose agar, and the following counts were obtained, and were recorded as shown in Figure 8. Total heterotrophic bacteria were evaluated from counts on Nutrient Agar plates (Table 11, Fig, 7). Industrial detergent utilizing bacteria was determined by culturing the sample on a minimal salt agar medium, and colony counts were obtained and recorded as shown in table 12 and figure 9.

\section{Discussion}

Physico-chemical properties of the habitat water

The results of some physical and chemical properties of the biodegradation set-up showed that differences in Hydrogen ion concentration $(\mathrm{pH})$ and organic carbon (biodegradable and chemically oxidizable) content of the three aquatic systems (fresh, brackish and marine) were not statistically significant at $95 \%$ probability levels (Table 3, 11). Thus the nutrient load of these aquatic systems did not offer any significant advantage to the indigenous microflora (Odokuma and Otukunafor, 2003; Nrior and Wosa, 2016). However, the alkaline $\mathrm{pH}$ range as well as mesophilic temperature range was observed to favour the acclimatization process for the native petroleum product-utilizing microbial population. These physic-chemical factors were particularly important for the survival of industrial detergent utilizing microbial consortium in the aquatic systems. These findings corroborated with the findings of Okpokwasili and Olisa (1991). With respect to sensory evaluation: General appearance of the fresh, brackish and marine water was clear; Odour, fresh water was unobjectionable while brackish and marine water was objectionable (Table 2). This could probably be due to oxidation of petroleum, detergents and other organic matter discharged on daily basis into the water body, since the aquatic area of study serve multiple purposes for oil and gas industry, manufacturing and fabrication industries etc. The Electrical Conductivity (EC), Total Hardness, Chloride, Total Dissolved Solids (TDS), Total Solids and Calcium of the three aquatic systems increased in the following order: Fresh water $<$ Brackish water $<$ Marine water while colour took the reverse order. Other parameters such as Total Alkalinity, Total Suspended Solids (TSS), Magnesium, Lead $(\mathrm{Pb})$ showed a decreasing order of Brackish water $>$ Marine water $>$ Fresh water while Biochemical Oxygen Demand (BOD) and Chemical Oxygen Demand (COD) showed an alternate trend: Brackish water $>$ Fresh water $>$ Marine water. This could be attributed to the presence and amount of organic matter present in the sample at the point of collection.

Microbiological evaluation during biodegradation of industrial detergents

Ten bacterial isolates obtained from different mixture of Industrial detergent; Teepol and Gamazyme with the different water (fresh, brackish and marine) samples were identified to belong to the following genera; Micrococus, Corynebacterium, Bacillus, Pseudomonas, Staphylococcus, Proteus, Escherichia, Citrobacter, Klebsiella and Enterobacter. Total heterotrophic bacteria count decreases from day 1 to day 20; with Teepol having the highest count $(6.30 \pm 0.93 \log 10 \mathrm{cfu} / \mathrm{ml})$ (Table 13). Statistical evaluation of the growth of THB result during the biodegradation of petroleum products revealed the following order: Total Heterotrophic Bacteria (THB - $\log 10 \mathrm{cfu} / \mathrm{ml})$ in fresh water: Teepol (6.60 \pm 0.31$)>$ Gamazyme $(6.12 \pm 1.06)$; brackish water: Gamazyme (6.68 \pm 0.14$)>$ T-pol $(6.64 \pm 0.24)$; marine water: Teepol $(6.30 \pm 0.93)>$ Control $(5.47 \pm 0.34)>$ Gamazyme $(5.27 \pm 1.60)$. Generally, this meant that the intermediates produce from the degradation of industrial detergents in these aquatic systems favoured the growth of a larger population of heterotrophic bacteria. Six genera of fungal isolates identified were - Aspergillus, Alternaria, Fusarium, Penicilium, RhizopusandMucor. The trend observed in THB was same with total fungal population. Statistical evaluation of the growth of total fungi (Table 13, Figure 8) during the biodegradation of petroleum products revealed the following; Total Fungi (TF - $\log 10 \mathrm{cfu} / \mathrm{ml})$ in freshwater: Teepol $(6.60 \pm 0.31)>$ Control $(6.37 \pm 0.19)>$ Gamazyme $(6.12 \pm 1.06)$; brackish water: Gamazyme $(6.68 \pm 0.14)>$ Teepol 
$(6.64 \pm 0.24)>$ Control $(6.40 \pm 0.21)$; marine water: Teepol $(6.30 \pm 0.93)>$ Control $(5.47 \pm 0.34)>$ Gamazyme $(5.27 \pm 1.60)$. These test industrial detergents showed mild increases and decreases in the total microbial (fungal) population in fresh, brackish and marine water used as inoculums. This observation is in agreement with the report of Okpokwasili and Nnubia (1995; Nrior and Wosa, 2016) that, oil spill dispersants support mild increases (stimulation) and decrease (inhibition) in the growth of specific heterotrophic marine bacteria. This response also applies to fungal population in this study. Responding to changes in the environment is a fundamental property of a living cell and chemotaxis is the best studied bacterial behavioural response that navigates the bacteria to niches that are optimum for their growth and survival (Bren and Eisenbach, 2000).

However, Okpokwasili and Odokuma (1990) have observed that biodegradation of oil spill dispersants in artificial media of varying $\mathrm{NaCl}$ concentrations $(0 \mathrm{mg} / \mathrm{l}$, $20,000 \mathrm{mg} / \mathrm{l}$ and $40,000 \mathrm{mg} / \mathrm{l})$ decreases with increase $\mathrm{NaCl}$ concentration. Acclimatization of the microbial population with industrial detergents components enhances the biodegradation efficiency of the microorganisms. Although bacterial population was more than fungal petroleum products degraders in the three aquatic systems, this agrees with previous findings of Okpokwasili and Olisa (1991), Amundet al. (1997), Nrior and Wosa (2016). The adaptability of native microbial population in the three aquatic systems to industrial detergents components would be the reason for their success at mineralizing the industrial detergent in the experimental set-up where the physico-chemical properties of the ecosystem were supportive to the survival of these microorganisms (Spain and van Veld, 1983).

Evaluation Industrial Detergent utilizing bacteria (IDUB) in the three aquatic systems (Table 12-13, Figure 9) revealed their population as follows: Industrial Detergent Utilizing Bacteria (IDUB - $\log 10 \mathrm{cfu} / \mathrm{ml}$ ) in fresh water: T-pol $(3.85 \pm 0.04)>$ Gamazyme $(2.93 \pm 0.47)>$ Control $(2.34 \pm 0.23)$; brackish water: T-pol (4.24 \pm 0.06$)>$ Gamazyme BTC $(4.04 \pm 0.25)>$ Control (3.90 \pm 0.38$)$; marine water: T-pol $(3.86 \pm 0.34)>$ Gamazyme BTC $(3.73 \pm 0.34)>$ Control (2.67 \pm 0.53$)$. The study revealed that Pseudomonas, Proteus, Micrococcus, Bacillus, Rhizopus, Asprgillus and Penicilium genera isolated from the tri - aquatic ecosystems were capable of utilizing industrial detergents as their carbon source. Similar trend in the ability of natural microbiota to degrade novel or synthetic compounds has been reported. Such similarity in the utilization of novel compounds by natural microflora is expected, since such breakdown depends on the possession of plasmids that are not naturally present in all microorganisms (Ogbuilieet. al., 2008). Hence, the ability to utilize xenobiotics must be dependent on the possession of the requisite enzymes necessary for such degradation (Nrior and Wosa, 2016).

Percentage (\%) ultimate biodegradation of petroleum products

Evaluation of percentage (\%) ultimate biodegradation at day 20; showed Industrial detergent - Teepol (71.2\%) to be more biodegradable in brackish water system while Industrial detergent- Gamazyme (31.1\%) in fresh water system is least (Figure 1). Comparatively, biodegradability potential of the petroleum products in the tri-aquatic systems at end of experiment (day 20) were; freshwater system (ultimate biodegradation - \%): Teepol (46.6) >Gamazyme (31.1); brackish water: Gamazyme (73.1) > Teepol (71.2); marine water: Teepol (55.6)>Gamazyme (44.7) (Figure 1, 6).

Percentage $(\%)$ ultimate biodegradation of the industrial detergents revealed a sharp and continuous decrease in the concentration of the sample from Day 5 until the end of the experiment (Table 9, Figure 4). The decrease observed in the test detergent samples is a clear indication that the test detergents were mineralized by the bacterial isolates and some fungal isolates, while that observed in the control sample may be as a result of decrease in nutrient concentration of the tri-aquatic systems. The results obtained however, reveals the ability of natural freshwater, brackish and marine bacterial isolates to degrade the two brands of industrial detergents (Gamazyme and Teepol) evaluated; though Gamazyme had a very low biodegradation potential.

\section{Conclusion}

This study reveals that the three aquatic systems (fresh water, Asarama Stream; Brackish water, Trans-Amadi Industrial Layout River and Marine water, Bonny River) are heavily impacted with toxic substances from oil companies constantly using these petroleum products in Rivers State and Nigeria in general. Brackish water has the highest comparative biodegradability potential followed by marine water and the least is the freshwater. Industrial detergent Gamazyme has a very low biodegradation potential especially in freshwater thus its use in the Nigeria Petroleum Industry should be with high caution.

It is therefore recommended that; current/new industrial detergents imported into Nigeria for use in upstream sector of the Nigeria Petroleum Industry should be assessed for it's biodegradability. Petroleum industries in Nigeria should always find out the aquatic environment that best degrade each new or re-formulated industrial detergents to be used, since each degrade at different rate in each environment.

\section{References}

[1] Amund, O. O., Ilori, M. O. andOdetunde, F. R. (1997). Degradation of CommercialDetergent products by microbial populations of the Lagos lagoon. Folia Microbiol. 42(4): 353-356.

[2] APHA, (1998). Standard Method for the Examination of Waste Water and Water. American Public Health Association. 19th Ed. Washington D.C.

[3] Bren, A. andEisenbach, M. (2000). How signals are heard during bacterialchemotaxis: protein-protein interactions in sensory signal propagation. Journal of Bacteriology. 182: 6865-6873. 
[4] Fuhrman, J. A. (1999). Marine Viruses and their biogeochemical and Ecological Effects. Nature 399:541-548.

[5] Holding, B. V. (2005). Detergents occurring in freshwater. $\mathrm{http} / / / \mathrm{www}$. lennetech.com/aquatic/detergents.htm.

[6] Lawson, R. J. and Payne, A. G., (1980). Fate of the Benzene, Ring of Linear Alkyl BenzeneSolphonate in Natural Waters. Appl. Environ. Microbiol. 41:21-22.

[7] Nigeria Environmental Study Action Team (NEST, 1991). Nigerians threatened environment: A nottems profile: pp 8488. A NEST Publication, Ibadan, Nigeria.

[8] Nrior, R. R. and Odokuma L. O. (2015) Ultimate Biodegradability potential of Trichloroethylene (TCE) used as Degreaser in marine, brackish and fresh water Journal of Environmental Sciences, Toxicology and Food Technology (IOSR-JESTET) www.iosrjournals.org9:80-89. doi: $10.9790 / 2402-09728089$

[9] Nrior R. R. and Wosa C. (2016) Biodegradation of oil spill dispersant in brackish water ecosystem of the Niger Delta, Nigeria. Journal of International Society of Comparative Education, Science and Technology (ICEST) 3(1):187-201

[10] Ogbulie T. E., Ogbulie J. N., and Umezurulke J. (2008) Biodegradation of Detergents by aquatic bacterial flora from Otamiri River, Nigeria. African Journal of Biotech 7(6) 824830.

[11] Okpokwasili, G. C. and Nwabuzor, C. N. (1988). Primary Biodegradation ofAniomic Surfactants in Laundry Detergents. Chemosphere 17: 2175 -2182.
[12] Okpokwasili, G. C. andNnubia, C. (1995). Effects of oil spill dispersants and drilling fluids on substrate specificity of marine bacteria, Waste. Manage. 7:515-520.

[13] Okpokwasili, G. C andOdokuma, L. O. (1990). Effect of Salinity on Biodegradation of oil Spill Dispersant, Waste. Manage. 10:141-146.

[14] Okpokwasili, G. C. andOlisa AO (1991). River-Water Biodegradation of Surfactants in Liquid Detergents and Shampoos. Water Res., 25:1425-1429.

[15] Okpokwasili, G. O. andOlisa, A. O. (1991). River water biodegradability of surfactants in liquid detergent and shampoos. Water Res. 25: 1425-1429.

[16] Olusola, A. O. and Benjamin A. A. (2009). Biodegradation of synthetic detergents in wastewater. African Journal of Biotech 8(6) 1090-1109.

[17] Prescott, L. M., Harley, J. and Klein, D. A. (2011). Microbiology fifth edition McGraw-Hill Companies.

[18] Spain, J. C. and Van Veld, P. A. (1983). Adaptation of natural microbialcommunities to degradation of xenobiotic compounds: effects ofconcentration, exposure, time, inoculum and chemical structure. Appl. Environ. Microbiol. 45: 428435 .

[19] Swisher, R. D. (1987). Surfactant Biodegradation. $2^{\text {nd }}$ ed. Marcel Dekker, New York. USA, pp. 130-142. 